\title{
Age and oral health: current considerations
}

\author{
Edad y salud oral: consideraciones actuales
}

\author{
Andrew Tawse-Smith(a) \\ (a) Associate Professor, Dean, Colegio \\ Odontologico Colombiano.
}

\section{Corresponding author:}

Andrew Tawse-Smith

Colegio Odontológico Colombiano

Cra 9 No. 13-40, Bogota, Colombia

E-mail: atawsesmith@odontologico.edu.co

\begin{abstract}
Dental plaque is still considered the main etiological factor for periodontal diseases. Our understanding of periodontal disease has advanced from the previous concepts where gingivitis slowly progressed to periodontitis to a more complex scenario that correlates several risk factors in the pathogenesis of periodontal disease. Among these factors, age has been associated with increased rates of periodontal disease as the population gets older. Although the loss of alveolar bone and periodontal attachment is common in the elderly population, and there is evident age-related changes in the periodontium, severe periodontitis is not a natural consequence of ageing. The importance of identifying the risk factors that participate in the pathogenesis of periodontal disease at an early phase, both of the individual and the disease, as well as evaluating the capacity of the individual to control dental plaque will enable the implementation of an adequate preventive program, where the needs and limitations of the individual are considered to specifically tailor the oral hygiene procedures and the mouthwashes to be used.
\end{abstract}

Descriptors: Age groups; Risk factors; Patient compliance; Periodontal diseases / prevention \& control; Antiseptics.

Resumen: La placa dental es aún considerada el factor etiológico primario de la enfermedad periodontal. La etiopatogenia de esta enfermedad ha avanzado del concepto anterior donde una gingivitis progresaba lentamente a una periodontitis, a un escenario más complejo donde varios factores de riesgo se correlacionan. Dentro estos factores, el envejecimiento ha sido asociado con mayores porcentajes de enfermedad periodontal a medida que la población envejece. Aunque la pérdida ósea y de inserción es común en el adulto mayor y los cambios del periodonto son evidentes con la edad, la enfermedad periodontal severa no es una consecuencia natural del envejecimiento. La importancia de identificar en una etapa temprana del individuo y de la enfermedad los factores de riesgo que participan en la patogenesis de la enfermedad periodontal, así como la evaluación de la capacidad del individuo para controlar la placa dental, permitirán la implementación de programas preventivos adecuados, donde las necesidades y limitaciones del individuo son consideradas para el establecimiento de procedimientos personalizados de higiene oral y el enjuague oral a utilizar.

Descriptores: Grupos por edad; Factores de riesgo; Colaboración del paciente; Enfermedades periodontales / prevención \& control; Antisépticos. 


\section{Introduction}

The biofilm that forms and remains on tooth surfaces is the main etiological factor in caries and periodontal disease. ${ }^{2,17}$ In recent years, it has become apparent that the pathogenesis of periodontal diseases is more complex than the mere presence of virulent microorganisms. The presence of risk factors is now considered an important aspect in the pathogenesis of periodontal disease. .111,12,25 $^{2}$

Susceptibility to periodontitis varies greatly between individuals who harbor the same pathogenic bacteria. Evidence points to the host response to bacterial challenge as a major determinant of susceptibility. ${ }^{11,12,25}$ Risk factors have been classified as modifiable or non-modifiable ones. Van Dyke ${ }^{25}$ (2005) considered modifiable risk factors those which are usually environmental or behavioral in nature, such as smoking, systemic conditions, microorganisms, periodontal disease and psychological factors such as stress, whereas non-modifiable are usually intrinsic to the individual and not easily changed, and they include genetics, host response and ageing, among other factors.

Although cross-sectional studies show more severe conditions in the older population, ${ }^{3}$ and other studies report the limited capacity of different age groups to maintain tooth surfaces free of dental plaque, ${ }^{6,23}$ there is a need to explore age related issues when implementing plaque-control measures and preventive programs in different age groups. Thus, the purpose of this review is to investigate if there is an impact of ageing on plaque control and oral health, and to propose specific preventive measures for different age groups.

\section{Age and oral health}

Although ageing has been associated with an increased incidence of periodontal disease, ${ }^{11,12}$ some studies have questioned the association between age and periodontitis. ${ }^{3,19,24}$ When the disease is measured by loss of periodontal attachment, nearly all cross-sectional studies show more severe conditions in the older population. ${ }^{3}$ Even though this loss of alveolar bone and periodontal attachment is common in the elderly population, severe periodontitis is not a natural consequence of ageing.
Studies in South American countries have shown similar findings as the ones stated previously, demonstrating a clear tendency towards increased rates of periodontal disease as the population gets older. ${ }^{5,9,10}$ Gjermo et al. ${ }^{10}$ (2002) reported that the distribution of dentate subjects with signs of moderate and severe periodontal disease increased with age. In this study, older subjects demonstrated higher percentages of periodontal disease in comparison with middle and younger age groups. Likewise, Flores-de-Jacoby et al..$^{5}$ (1991) showed that between 41 and $51 \%$ of the subjects in the older age group had signs of moderate and severe periodontal diseases. However, in this study, $50 \%$ of the subjects in the young age group also showed signs of moderate periodontal disease. In a Chilean population, Gamonal et al. ${ }^{8}$ (1998) reported that periodontal conditions were poorer than in developed countries. The age groups 35-44 and 65-74 showed high prevalence values of chronic periodontal disease, $92 \%$ and $100 \%$ respectively.

Various studies have shown that, at an early age, there is minimal localized initial loss of attachment; at the age of 30 , the cumulative loss of attachment reaches $1 \mathrm{~mm}$; and as the participants approach 40 years, the mean loss reaches $1.5 \mathrm{~mm} \cdot{ }^{13,15,16,20}$ Schatzle et al. ${ }^{20}$ (2003) evaluated the pattern, rate, and variations of attachment loss during various stages of adult life. Their results demonstrated that participants started with a healthy periodontium; at early twenties, less than $10 \%$ of the sites lost periodontal attachment; for the next 30 years, more sites were affected; and as they reached 60 years, approximately $75 \%$ of the sites showed an attachment loss of $2 \mathrm{~mm}$. Although a high percentage of the sites showed attachment loss, there were $25 \%$ of the men who, during their entire 60 years of life, did not develop chronic periodontal disease beyond gingivitis, and basically went through adult life with a healthy periodontium. It is apparent from the previous studies that older age groups have a higher prevalence of periodontal disease. However, to understand the events that participate in the initiation and progression of periodontal disease, it is necessary to take into account the susceptibility of the individual, the cumulative nature of loss of periodontal support, the length of exposure to 
etiologic factors, the rate of progression, the repair process, tissue changes, compliance, dexterity, and socioeconomic levels, among other factors, which have been discussed in the literature. ${ }^{3,10,14,24}$ Johnson $^{14}$ (1989) reported that the effects of previous loss of periodontal attachment and bone loss accumulate with age and that the evidence that the susceptibility to periodontal destruction increases with age is not clear. Additionally, Van der Velden ${ }^{24}$ (1984) reported that, with age, the periodontium can react differently to plaque, where inflammation develops more rapidly and healing proceeds more slowly. This study concluded that there is age related changes in the periodontium, but that individual susceptibility is more important than the age effect.

The previous findings suggest that age alone is not a major factor in the development of periodontitis and that it is essential to have additional risk factors to initiate and have progression of periodontal disease. Identifying risk factors for loss of periodontal support and dental function requires a multivariate analysis, preferably with genetic, biological, clinical and environmental factors. It is important to identify the risk factors that participate in the pathogenesis of periodontal disease at an early phase, both of the individual and the disease, to enable the implementation of an adequate preventive program, where the needs of the individual and/or each age group are considered to specifically tailor the oral hygiene procedures and mouthwashes to be used.

Axelsson et al. ${ }^{2}$ (2004) reported that the tendency of studies in the 1970s both in children and adults was to prevent or retard the development of caries and/or gingivitis/periodontitis through the use of plaque control methods. In this study, after 30 years of being enrolled in a preventive program, the overall plaque scores in the different age groups (Group 1: 20 - 35, Group 2: 36 - 50, and Group 3: $51-65)$ reduced from baseline levels of $50-60 \%$ to levels below $20 \%$. This study concluded that the preventive program improved the dental health for all age groups.

In contrast, the results reported by Schatzle et al. ${ }^{20}$ (2003), where $25 \%$ of the men during their entire life did not develop chronic periodontal disease beyond gingivitis and basically went through adult life with a healthy periodontium, demonstrate that the progression of periodontal disease may not occur even if personal oral hygiene is not completely effective. It seems that progression differences seen between individuals of the same or different age group should be considered when implementing preventive programs and/or indicating oral hygiene procedures with the adjunctive use of mouthwashes containing chemotherapeutic agents.

Other studies support the clear advantages of adequate oral hygiene practices and regular dental care as shown in the study of Axelsson et al. ${ }^{2}$ (2004). Streckfus et al. ${ }^{22}$ (1999) demonstrated that the integrity of the periodontium could be maintained throughout life by exercising comprehensive oral hygiene practices and routine dental care. Furthermore, Eneroth, Sundberg ${ }^{4}$ (1985) recalled more than 900 subjects during a 5 -year interval and reported stable periodontal conditions during the observation period. Likewise, Söderholm ${ }^{21}$ (1979) reported low incidence of caries when subjects were recalled every 3 months for education and training in plaque control measures and related scaling and root planing. When subjects were enrolled in the preventive program, the number of new decayed surfaces was reduced from 0.4 to 0.17 lesions/year. On the other hand, for those subjects who are not enrolled in preventive programs, a higher incidence of caries and periodontal disease has been reported. ${ }^{7,18}$ Fure $^{7}$ (2003) showed a higher incidence of coronal and root caries for subjects between 55 and 75 years of age. It is obvious from the results of these studies that preventive dental care programs and oral health education may have a marked influence on sound tooth surfaces.

Additionally, the limited capacity of the different age groups to maintain the tooth surfaces free of dental plaque is a factor to be considered when indicating plaque-control measures. ${ }^{6,23}$ Freitas-Fernandez et al. ${ }^{6}$ (2002) showed, in a group of Brazilian children aged 7-11, unsatisfactory levels of plaque and gingival inflammation control even after being enrolled in a preventive program. The results showed that the children enrolled in the preventive program still had $32 \%$ of the dental surfaces covered with dental plaque. Likewise, Tawse-Smith et al. ${ }^{23}$ (2002) reported that elderly participants between 55 and 80 
years of age were moderately effective in removing dental plaque when carrying out self-performed oral hygiene practices, even after receiving detailed video and written instructions for the use of different toothbrushes. Their results showed the limited capacity of the participants in removing dental plaque from implant surfaces irrespective of the mechanical device used. Mechanical methods of plaque control require dexterity, motivation, compliance and time. These studies clearly demonstrate that most of the individuals may find beneficial effects in the use of an adjunctive essential oil mouthwash in order to improve their self-performed oral hygiene.

\section{Conclusions}

Irrespective of the age group considered, it is essential to understand which risk factors are involved in the initiation and progression of caries and periodontal disease. It is important to analyze which preven-

\section{References}

1. Albandar JM. Global risk factors and risk indicators for periodontal diseases. Periodontol 2000. 2002;29:177-206.

2. Axelsson P, Nystrom B, Lindhe J. The long-term effect of a plaque control program on tooth mortality, caries and periodontal disease in adults. Results after 30 years of maintenance. J Clin Periodontol. 2004;31(9):749-57.

3. Burt BA. Periodontitis and Aging: Reviewing Recent Evidence. J Am Dent Assoc. 1994;125:273-9.

4. Eneroth L, Sundberg H. [The effect of preventive dentistry performed by specially trained dental hygienists - a pilot study][Article in Swedish]. Tandläkartidningen. 1985;77:747.

5. Flores-de-Jacoby L, Bruchmann S, Mengel R, Zafiropoulos GG. Periodontal conditions in Rio de Janeiro City (Brazil) using CPITN. Community Dent Oral Epidemiol. 1991;19:1278.

6. Freitas-Fernandes LB, Novaes Junior AB, Feitosa AC, Novaes AB. Effectiveness of an Oral Hygiene Program for Brazilian Orphans. Braz Dent J. 2002;13(1):44-8.

7. Fure S. Ten-year incidence of tooth loss and dental caries in elderly Swedish individuals. Caries Res. 2003;37:462-9.

8. Gamonal JA, Lopez NJ, Aranda W. Periodontal Conditions and treatment needs, by CPITN, in the 35-44 and 65-74 year-old population in Santiago, Chile. Int Dent J. 1998;48:96-103.

9. Gasparini DO, Buri MH. Determinacion de las necesidades terapeuticas periodontales en la comunidad de Corrientes, Repu- tive program should be indicated for each individual or age group based on their needs, risks and limitations. A younger age group may find beneficial effects in being enrolled in preventive programs, which include the use of mouthwashes as a complement of the daily oral hygiene routine for controlling bacterial plaque. For this purpose, mouthwashes should include chemotherapeutic agents such as essential oils and fluoride because caries may be a higher risk at this age. A middle age group may find more advantages in using mouthwashes that control dental plaque and gingival inflammation because individuals at this age may present a higher risk of developing periodontal disease. For the older age groups, adjunctive mouthwashes should be indicated to help prevent root caries and periodontal disease. It is clear that subjects who are not enrolled in preventive programs experience a much higher incidence of caries and periodontal disease than carefully maintainer subjects.

blica Argentina. Revista la Asosiacion Odontologica Argentina. 1998;86:349-54.

10. Gjermo P, Rosing CK, Susin C, Oppermann R. Periodontal diseases in Central and South America. Periodontol 2000. 2002;29:70-8.

11. Grossi SG, Genco RJ, Machtei EE, Ho AW, Koch G, Dunford $\mathrm{R}$ et al. Assessment of risk for periodontal disease. II. Risk indicators for alveolar bone loss. J Periodontol. 1995;66:239.

12. Grossi SG, Zambon JJ, Ho AW, Koch G, Dunford RG, Machtei EE et al. Assessment of risk for periodontal disease. I. Risk indicators for attachment loss. J Periodontol. 1994;65:2607.

13. Ismail AI, Morrison EC, Burt BA, Caffesse RG, Kavanagh MT. Natural history of periodontal disease in adults: findings from the Tecumseh Periodontal Disease study, 1959-87. J Dent Res. 1990;69:430-5.

14. Johnson NW. Detection of high-risk groups and individuals for periodontal diseases. Int Dent J. 1989;39:33-47.

15. Löe H, Ånerud A, Boysen H, Morrison E. Natural history of periodontal disease in man. Rapid, moderate and no loss of attachment in Sri Lankan laborers 14 to 46 years of age. J Clin Periodontol. 1986;13:431-45.

16. Löe H, Ånerud A, Boysen H, Smith M. The natural history of periodontal disease in man. The rate of periodontal destruction before 40 years of age. J Periodontol. 1978;49:607-20. 
17. Löe H, Theilade E, Jensen SB. Experimental gingivitis in man. J Periodontol. 1965;36:177-87.

18. Lovdal A, Arno A, Schei O, Waerhaug J. Combined effect of subgingival scaling and controlled oral hygiene on the incidence of gingivitis. Acta Odontol Scand. 1961;19:537-55.

19. Page RC. Periodontal diseases in the elderly: a critical evaluation of current information. Gerodontology. 1984;3:63-70.

20. Schatzle M, Loe H, Lang NP, Heitz-Mayfield LJ, Burgin W, Anerud A et al. Clinical course of chronic periodontitis. III. Patterns, variations and risks of attachment loss. J Clin Periodontol. 2003;30:909-18.
21. Söderholm G. Effect of a dental care program on dental health conditions. A study of employees of a Swedish shipyard [Thesis]. Lund University; 1979.

22. Streckfus CF, Parsell DE, Streckfus JE, Pennington W, Johnson RB. Relationship between oral alveolar bone loss and aging among African-American and Caucasian individuals. Gerodontology. 1999;45:110-4.

23. Tawse-Smith A, Duncan WJ, Payne AG, Thomson WM, Wennström JL. Relative effectiveness of powered and manual toothbrushes in elderly patients with implant-supported mandibular overdentures. J Clin Periodontol. 2002;29:275-80.

24. Van der Velden U. Effect of age on the periodontium. J Clin Periodontol. 1984;11:281-94.

25. Van Dyke TE, Sheilesh D. Risk Factors for Periodontitis. J Int Acad Periodontol. 2005;7(1):3-7. 